\title{
Proceeding
}

Supplementary Issue: Autumn Conferences of Sports Science. Costa Blanca Sports Science Events, 18-19 December 2020. Alicante, Spain.

\section{Outdoor movement education during COVID-19: What kindergarten teachers think}

\author{
PATRIZIA TORTELLA ${ }^{1} \unlhd$, ROSARIA SCHEMBRI², DANIELE COCO ${ }^{3}$, MARIO LIPOMA ${ }^{2}$ \\ ${ }^{1}$ Free University of Bolzano, Italy \\ 2University of Enna "Kore", Italy \\ 3University of Roma Tre, Italy
}

\begin{abstract}
During the lockdown physical activity had a decline. What is the status now? A questionnaire was administered to 69 kindergarten teachers in 11 Italian regions to investigate the outdoor physical activity of children. Twenty-six percent of them report that they implement activities in their school garden (67\% have a space larger than $150 \mathrm{sqm}$ ) or park; $42 \%$ report that children engage in 3 to 7 hours of physical activity per week, $51 \%$ from 1 to 2 hours per week, and 7\% do no practice physical activity. In September-October $11 \%$ of teachers never go outside, in November-December 22\% and in March-June 15\%. 52\% of teachers believe that children should not be taken outdoors because of cold, wind, or rain and $30 \%$ of parents agree that it is better if children do not go outside. $76 \%$ of teachers say that it is important for children to have contact with nature and $90 \%$ of teachers say that outdoor activities are not risky. Although teachers report that outdoor activities are a resource for kindergarten the data do not support this.

Keywords: Outdoor education; Kindergarten; Physical activity; Outdoor movement education; COVID-19; Parks.

\section{Cite this article as:}

Tortella, P., Schembri, R., Coco, D., \& Lipoma, M. (2021). Outdoor movement education during COVID19: What kindergarten teachers think. Journal of Human Sport and Exercise, 16(2proc), S752-S762. doi:https://doi.org/10.14198//hse.2021.16.Proc2.61
\end{abstract}

Corresponding author. Free University of Bolzano, Italy. https://orcid.org/0000-0002-2553-9163

E-mail: patrizia.tortella@gmail.com

Abstract submitted to: Autumn Conferences of Sports Science. Costa Blanca Sports Science Events, 18-19 December 2020. Alicante, Spain.

JOURNAL OF HUMAN SPORT \& EXERCISE ISSN 1988-5202

(c) Faculty of Education. University of Alicante

doi:10.14198/jhse.2021.16.Proc2.61 


\section{INTRODUCTION}

In March 2020, the World Health Organization declared Pandemic status for Covid-19. Measures to contain the infection, such as the use of masks, hand cleaning or gloves, and social distances were introduced. As the problem arose in many European countries, a lockdown was made, requiring people to stay in their homes. Quarantine was then introduced, i.e., isolation in case of infection or positivity to the virus, even if asymptomatic. In Italy law n. 6 of February $23^{\text {rd }}, 2020$ suspended all public events including schools, gyms, meeting places. On March $11^{\text {th }}, 2020$, the decree "I stay at home" was issued. All sports, motor and recreational activities were suspended, it was allowed to leave the house for serious and documented reasons. On May fifth, 2020 Italy entered phase 2: the schools were still closed, the sports centres and gyms reopened with appropriate safety and containment measures. From June $15^{\text {th }}$ to October $7^{\text {th }}, 2020$, Italy entered phase 3 (decree-law July 30th, 2020), named: coexistence with Covid-19. The summer centres reopened, sports, motor and recreational activities resumed and the obligations to keep interpersonal distance, use of masks, disinfect hands remained. From October 8th to January $31^{\text {st }}, 2021$ there was the second wave of Covid-19 and the more restrictive measures were resumed, with closure of gyms and sports centres. The pandemic has resulted in numerous deaths and confinement measures have generated psychological problems, especially in children and young people, such as sleep problems, stress and anxiety (Giallonardo et al., 2020). Staying closed in one's own home caused a reduction in light exposure, which resulted in a change in lifestyle habits, such as mealtimes and sleep. These changes in the circadian biological rhythm can cause major cardiometabolic consequences (King et al., 2020). Though the situation for the youngest (under the age of 12) has been studied, very little is available and just few researches focus on the psychological, motor, scholastic consequences in children (Cachón-Zagalaz et al., 2020). The significant reduction in physical activity (Bates et al., 2020) represents one of the major problems of COVID19. Indeed, reduction and lack of physical activity is known to be associated to increased risk of noncommunicable diseases, such as cardiovascular, metabolic, cancer, type 2 diabetes (WHO, 2008, 2019); negative consequences also occur at the level of development of motor skills, bone density, emotional/psychological regulation of health (Janssen et al. 2010). Some studies (Roman-Viñas, 2016) highlight that prior to COVID-19, less than $10 \%$ of children aged $5-17$ years were achieving the recommendations on the amount of daily physical activity recommended by the World Health Organization (2018). Specifically, the WHO recommends 60 minutes per day of vigorous and intense activity and muscle strength activities at least 3 times per week. Spending hours in the light is also recommended (Tremblay et al., 2016). Activities at home with daily school hours spent in front of a PC or TV screen has made it difficult for children to engage in physical activity. A Canadian study found that only $3.6 \%$ of children were able to achieve the required level of physical activity, during the pandemic (Guan et al., 2020). An interesting Croatian study (Zenic et al., 2020) showed a major decline in physical activity in children by comparing data in the period before the first phase of Covid-19 (October 2019-March 2020) with those in the period after (after April 2020). Specifically, this study found that the greatest decline occurred in children living in urban areas, compared with those living in rural areas. The rural setting appears to favour opportunities for outdoor activities, where it is easier to maintain social distances and other safety measures during the pandemic. Bates et al., 2020 highlights the importance of taking the social-ecological model view in order to understand the effects of the pandemic and to think about possible solutions. It is critical to take into account the role of the physical environment, human context, local politics, children's and parent beliefs, habits, interests and motivation, and other factors because it is known that environment, parents and teachers assume a critical role in child development. Research confirms that outdoor physical activity is very valuable because in addition to promoting a decrease in depressive symptoms, anxiety, stress and boredom, it encourages easy compliance with interpersonal distances (Park et al., 2020) and can promote cognitive functions (Tortella et 
al., 2017). Children need to engage in physical activity to improve their motor skills (Sgrò et al., 2017,2020). Improving motor skills contributes to increased physical activity (Haga et al., 2018, Tortella et al., 2016, 2019).

With this article we want to investigate the physical activities carried outdoor in Italian kindergartens during the period of the restarts of school activities, i.e., from September 2020. During this period, inside physical activities were very limited, with several constrains and not recommended by the Public Health authority.

\section{METHODS}

Questionnaires constructed at hooch were administered to 69 teachers of kindergartens in 11 Italian regions, to investigate the physical activity carried outdoor in Italian kindergartens during the period SeptemberDecember 2020. The questionnaire was administered online, using the platform, Survey Monkey.

The project was examined by the Scientific Committee of A.S.D. Laboratorio 0246, the non-profit Association that organized a training for kindergarten teachers. The Scientific committee verified the adherence to the principles of the Declaration of Helsinki and approved the study. All the teachers received a description of the questionnaire. Written informed consent was obtained before administering the questionnaires.

\section{RESULTS}

The Italian participating teachers who responded to the questionnaire work in preschools in the following regions of Italy: Friuli Venezia Giulia (2), Piemonte (1), Lombardia (6), Veneto (6), Emilia Romagna (6), Lazio (2), Molise (1), Campania (1), Basilicata (1), Sicilia (18), Sardegna (3).

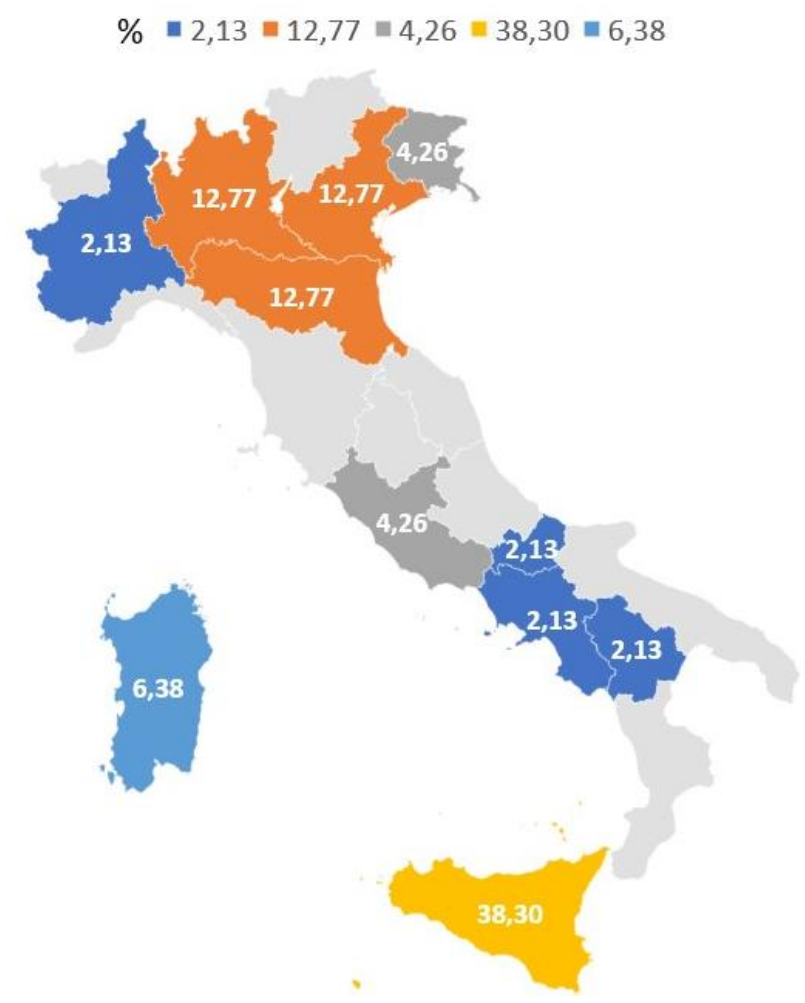

Figure 1. Percentage of Italian kindergartens participating in the project. 


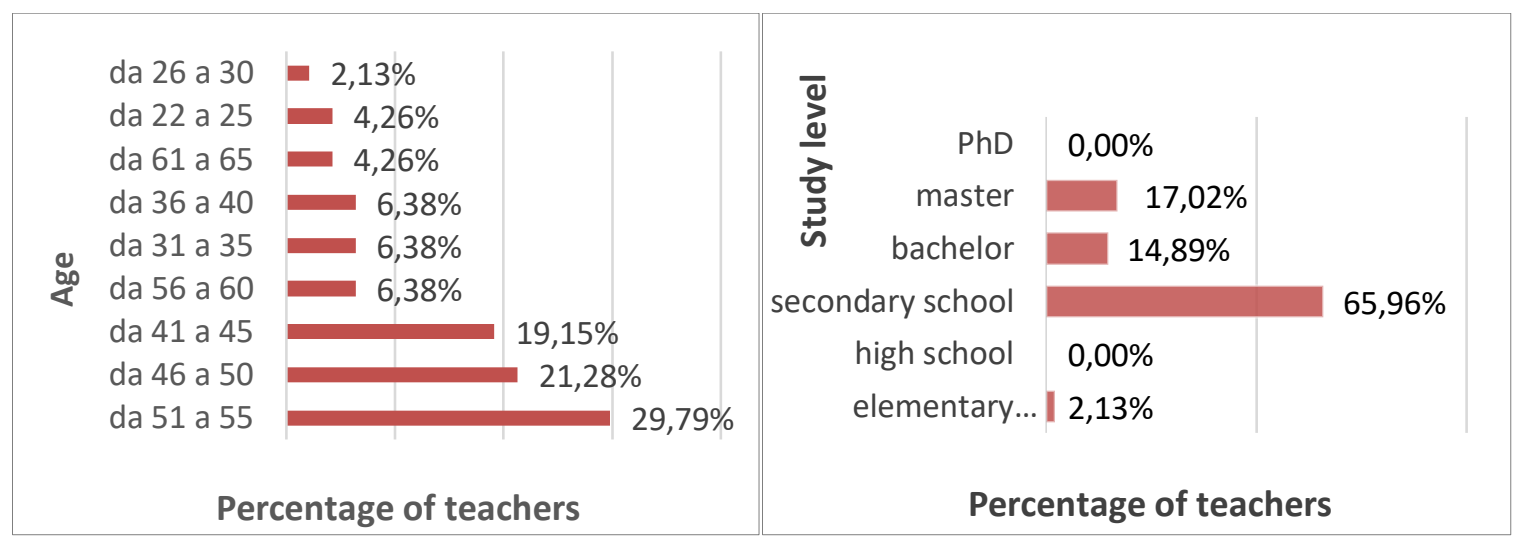

Figure 2. Age of Kindergarten teachers.

Figure 3. Study level of Kindergarten teachers.

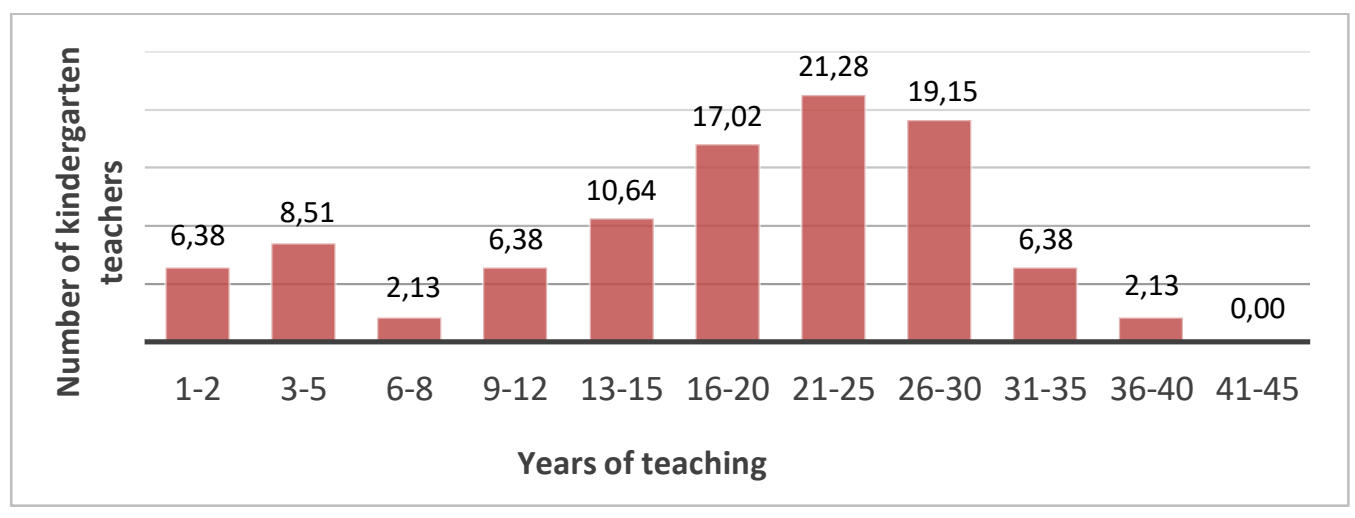

Figure 4. Years of teaching of kindergarten teachers.

Teachers participating in the project were 1 male and 46 females and were involved in a national training on early childhood motor activities. Six teachers held a bachelor's degree in exercise science, in addition to their kindergarten teaching qualification. $72.34 \%$ of the teachers practiced sports at the recreational level and $23.40 \%$ at the competitive level. $8.54 \%$ of teachers have coached a sports team at least once, $14.89 \%$ are coaching now, and $76.60 \%$ have never coached.

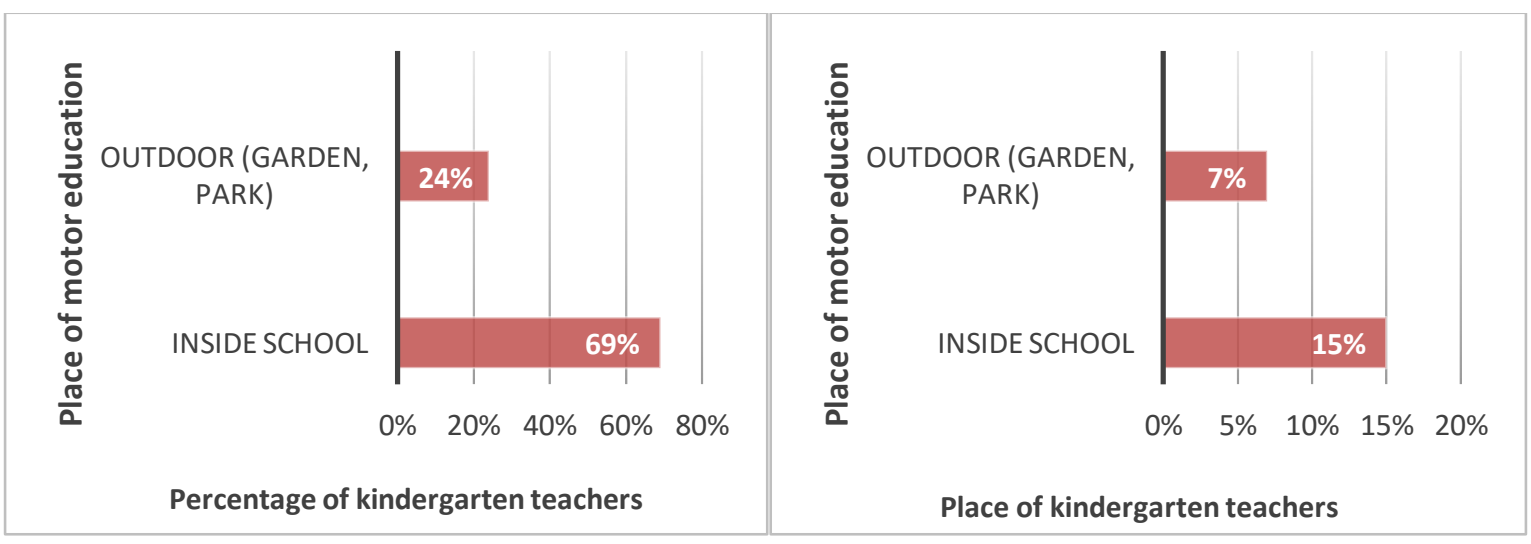

Figure 5. Place where children do motor activity in the morning.

Figure 6. Place where children do motor activity in the afternoon. 
$68.9 \%$ of teachers report that physical education class is planned at school, while $31.91 \%$ do not. $80 \%$ of teachers teach motor education to their class and $20 \%$ instead utilize a professional in physical activity from outside the school.

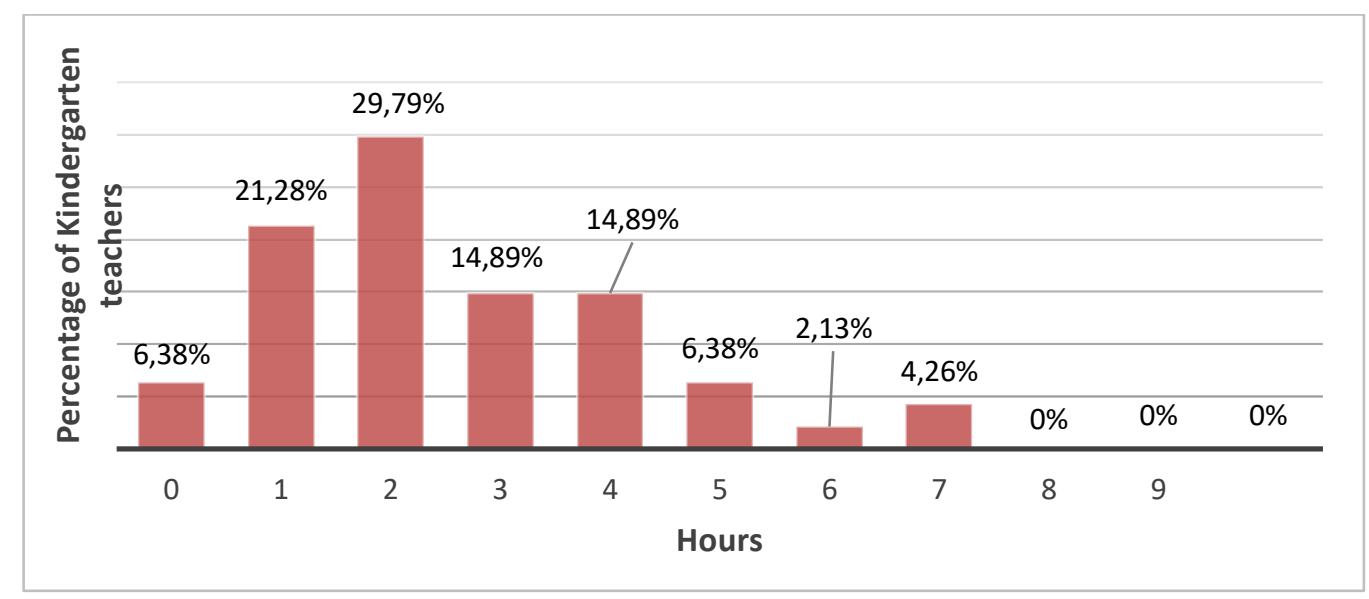

Figure 7. Hours of motor education per week in November-December 2020.

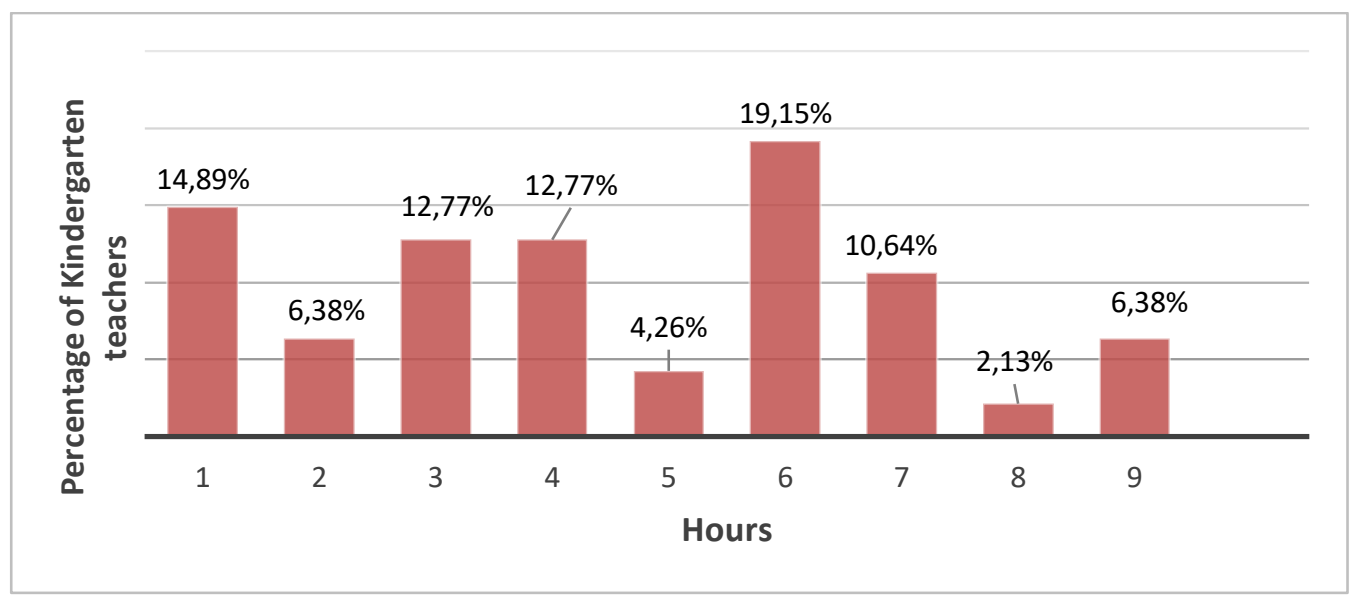

Figure 8. Preschool teachers report that children play freely, doing movement activities during other times of the week as well.

$36.17 \%$ of the preschool teachers surveyed responded that their kindergarten has a school gym for physical activity, while $63.83 \%$ stated that they do not have a gym.

Of those teachers who have a gym in preschool only $30 \%$ can use it $100 \%$ of the time of the week, $70 \%$ of teachers can use it 20 to $50 \%$ of the time. In fact, the same gym is also used by the elementary school, middle school, for sports and non-motor activities. 


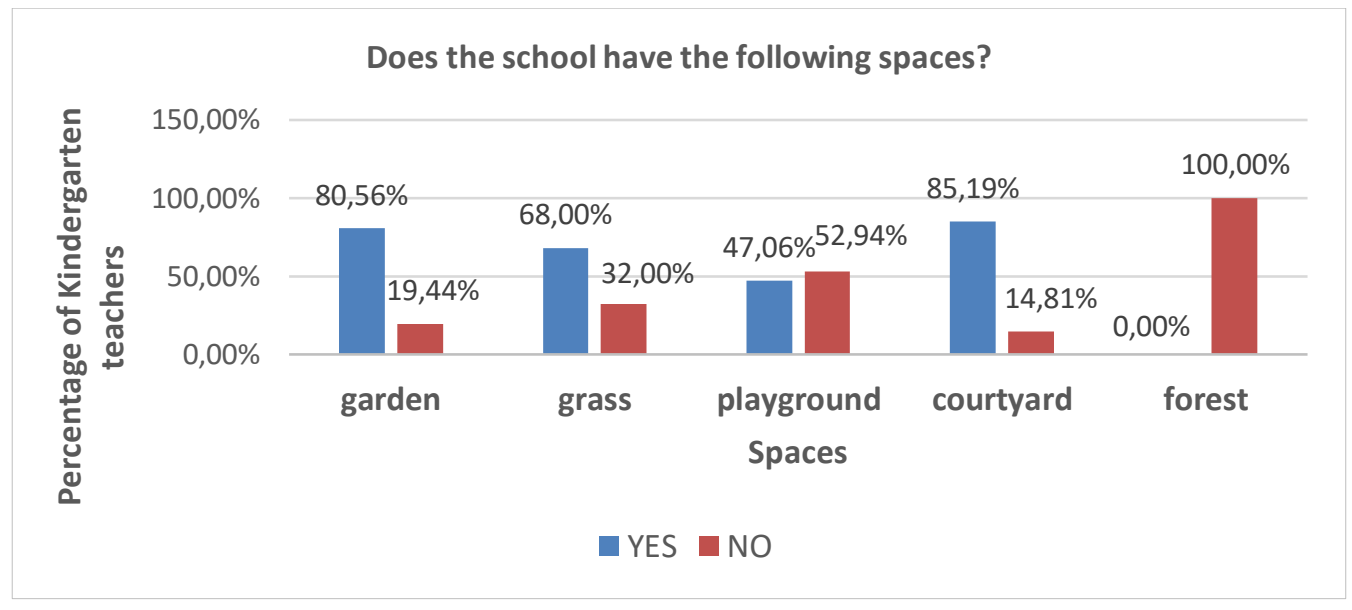

Figure $9.80 \%$ of preschools have a garden, adjacent to the school; about $60 \%$ have a lawn, about $40 \%$ have a playground, more than $80 \%$ have a courtyard. None of the schools have the forest adjacent.

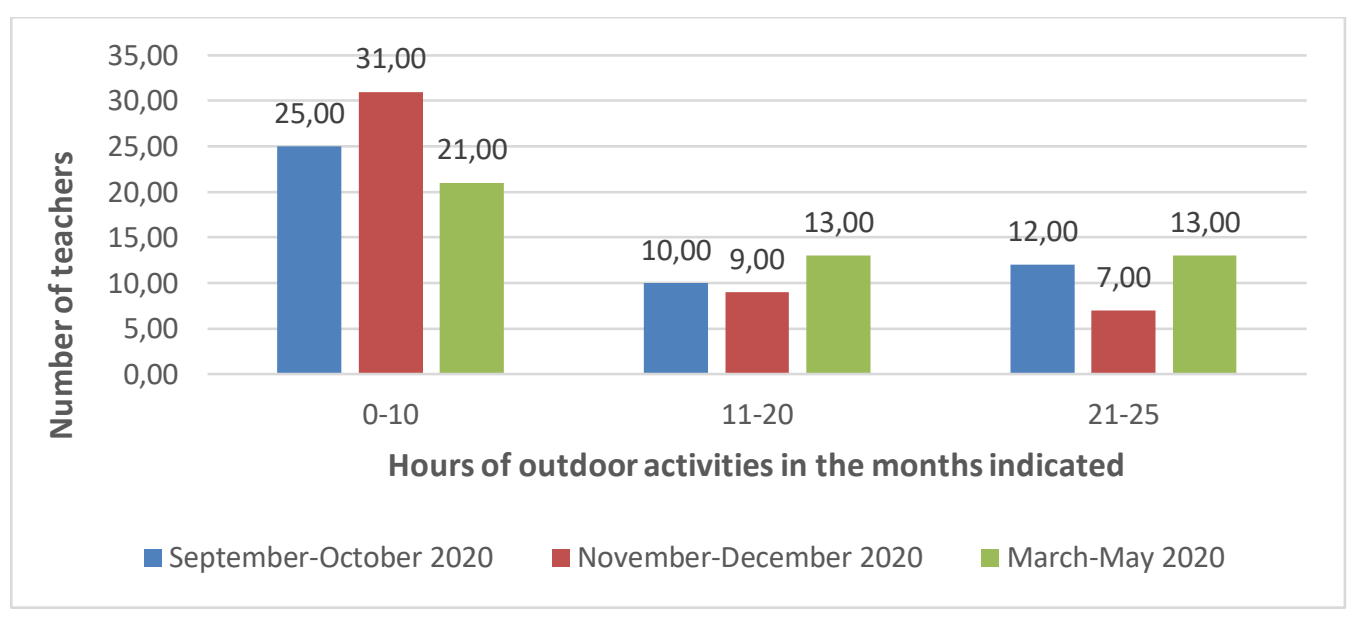

Figure 10. Ours outdoor in the months September-October 2020, November-December 2020, March-May 2020.

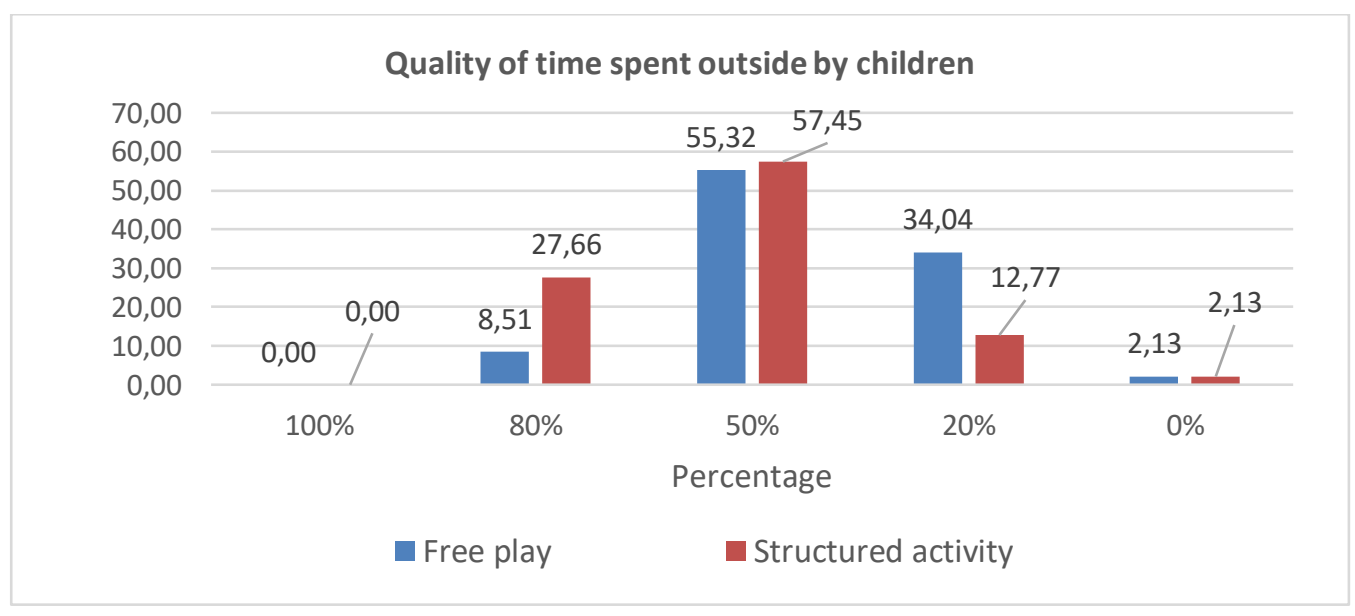

Figure 11. Quality of time spent outside by children. 
Most teachers report going outdoors with children primarily in September-October 2020 and going out less in November, December. In the months of March-May 2020, the lockdown period, while outdoor activities were recommended, children got out very little for the majority of teachers. In the three months of March, April, and May, most children performed outdoor activities from 0 to 10 hours.

$50 \%$ of the teachers interviewed take their children outside, doing structured activities and free play half the time. $20 \%$ spend more time with free play than structured play.

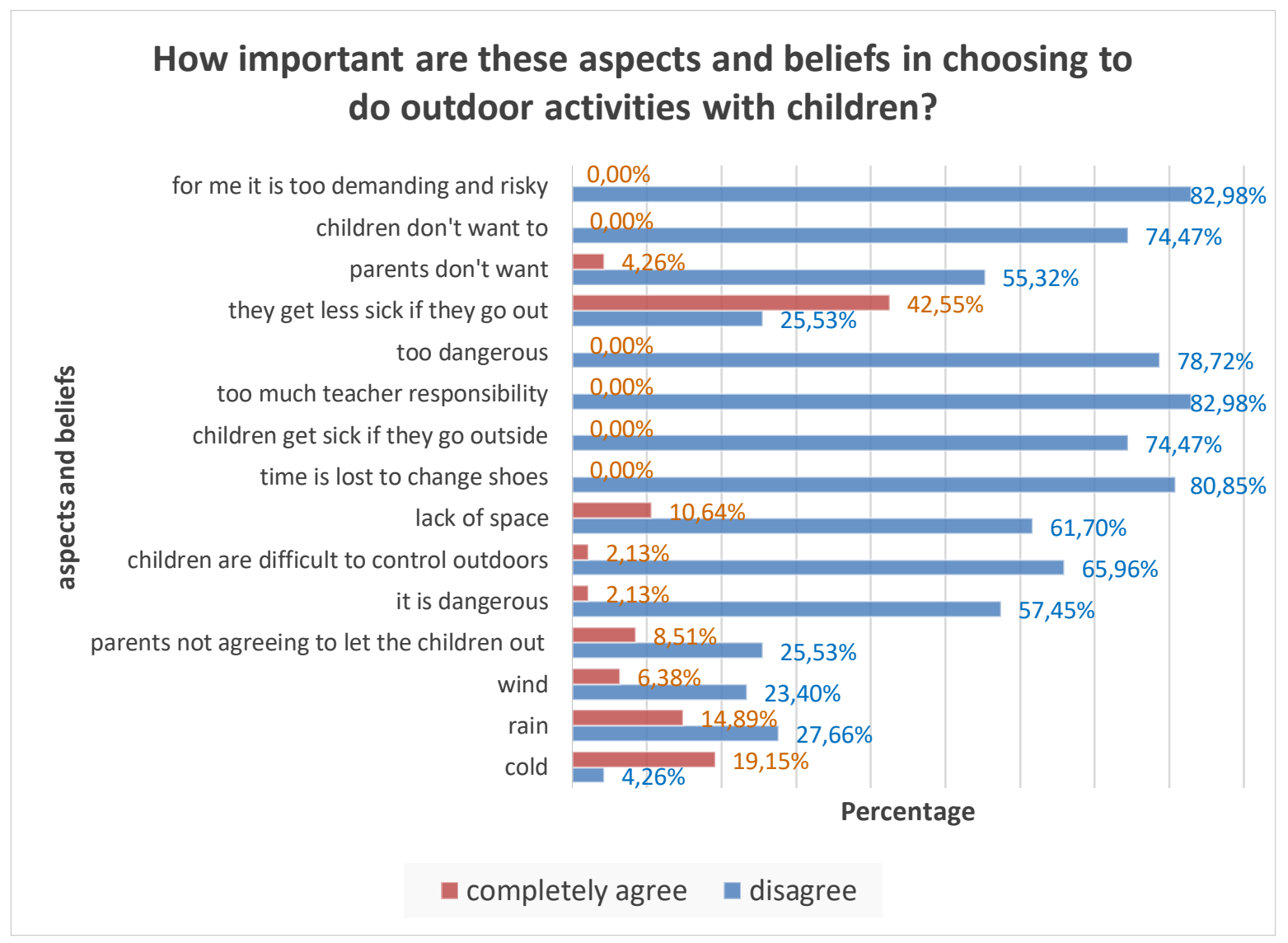

Figure 12. Aspects and beliefs that may affect the choice to engage in outdoor activities.

Teachers were then asked questions. To the question, "What has changed with COVID-19 in physical activity with pre-schoolers", they answered:

- "A total disruption.

- Need more attention from the point of view of care and hygiene.

- I have decided with colleagues to spend most of my time in the garden, even during normal daytime activities.

- Nothing has changed, I do the same things as before.

- Little space available to have to share with other sections.

- Avoiding excessive contact games.

- We had to give up psychomotor skills because of the spacing rules.

- Nothing because spacing is not provided.

- Physical activity takes place only between children in the same class. 
- We only do activities outdoors and with natural materials.

- In my opinion there is more awareness of the importance of movement and physical activity.

- Fear and limitation of physical contact.

- Less space available.

- I Cannot do activities on the ground with mattresses.

- Activities have been almost completely suspended".

These responses were repeated by several teachers.

Teachers were asked what they learned during this lock down period and the most frequent response is:

- "This difficult situation has allowed us to look for new strategies, and the outdoor environment is a good Solution to take better advantage of.

- Physical activity should be a mandatory appointment for all children because it is joy and helps to Control their emotions. It would be useful to apply it every other day.

- It would be good to provide more information regarding outdoor activity, especially for the use of families.

- Outdoor Motor Trails.

- Make motor activity mandatory in preschool.

- Improve relaxation and mindfulness practices".

Certainly, the support of experts and compulsory training for teachers on the value of motor practice for the development of cognitive sphere in children and the acquisition of skills preparatory to the attendance of compulsory schooling would be of fundamental importance in order not to leave to chance and improvisation the practice of the activity and revolutionize in some cases the entire methodologicaldidactic structure.

\section{DISCUSSION AND CONCLUSIONS}

Teachers report that the pandemic period in addition to be a difficult time is also a time of learning new situations and strategies. They report in large numbers that outdoor activity is very important and should be more developed. they complain about the lack of experience and specific knowledge with respect to the possibilities of physical activity and recognize its importance. The numerical data show that despite the importance attached to physical activity and the outdoor environment only a minority of teachers spent time outdoors and continued physical activity, especially in March-April-May 2020, when the situation in COVID-19 was very critical. In addition, it can be argued that very little physical activity has been practiced and below international recommendations on health and physical activity (WHO, 2019). No teacher has noticed the decrease in physical activity, and many say nothing has changed during the pandemic compared to before. There are also conflicting answers on several aspects that highlight a lack of knowledge and clarity regarding the need to practice physical activity. International recommendations were never mentioned. The incomplete consistency of the answers given, also with reference to social distancing, reveals a situation of not easy approach to the current legislation, which affects the choice of opportunities and practices. The teacher's role as mediator (Fumagalli et al., 2020; Tortella, 2017) is particularly important in this period, to help children in difficult situations, even from a psychological point of view. It is particularly difficult for them to be able to explain what is happening and it is essential to establish synergies with families (Casolo et al., 2019). 
A training course on the importance of physical activity (D'Elia, 2019, 2020) and its possibilities in outdoor environments is certainly recommended and useful. At this time, it is also possible that teachers' learning abilities are particularly influenced by the situation and the desire for change (Notarnicola et al., 2012). A clarifying approach to language and the various aspects of physical and outdoor activity is also necessary.

\section{AUTHOR CONTRIBUTIONS}

T.P.: Conceptualization, Methodology, Data curation, Writing-Review \& Editing, and Supervision. S.R.: Conceptualization, Investigation, Formal Analysis, Writing-Original Draft Preparation. C.D.: Conceptualization, Methodology, Formal Analysis, Writing-Original Draft Preparation. M.L: Conceptualization, Writing-Review \& Editing, and Supervision.

\section{DECLARATION}

All authors have read and agreed to the published version of the manuscript and declare that the material submitted is original and unpublished and is not under consideration for publication elsewhere. They declare that no competing interests exist, and that they received no specific funding for this work.

\section{ACKNOWLEDGMENTS}

We thank A.S.D Laboratorio 0246 and Center for Research in Child Motor Development CRSMI for the local organization.

\section{REFERENCES}

Bates, LC., Zieff, G., Stanford, K., Moore, JB., Kerr, ZY., Hanson, E.D., Gibbs, BB., Kline, CE., \& Stoner, L., (2020). COVID-19 Impact on Behaviors across the 24-Hour Day in Children and Adolescents: Physical Activity, Sedentary Behavior, and Sleep. Children, 7, 138. https://doi.org/10.3390/children7090138

Cachón-Zagalaz, J., Sánchez-Zafra, M., Sanabrias-Moreno, D., González-Valero, G., Lara-Sánchez, AJ.,\& Zagalaz-Sánchez, ML., (2020). Systematic Review of the Literature About the Effects of the COVID-19 Pandemic on the Lives of School Children. Front Psychol. https://doi.org/10.3389/fpsyg.2020.569348

Casolo, F., Coco, D., Frattini, G., Vago, P., Casolo, A., (2019). Effective teaching competences in Physical Education, Journal of physical education and sport, 19, 1806-1813. https://doi.org/10.7752/ipes

Decree 04 maggio 2020 - GU Serie Generale n.115 del 06-05-2020) Retrieved from: https://www.gazzettaufficiale.it/eli/id/2020/05/06/20A02526/sg

Decree-Law 30 luglio 2020, n. 83. G.U. 28/09/2020, n. 240 Retrieved from: https://www.gazzettaufficiale.it/eli/id/2020/07/30/20G00112/sg

Decree-Law: $\quad$ February $23, \quad 2020 . \quad$ Retrieved from: http://www.gazzettaufficiale.it/eli/gu/2020/02/23/45/sg/pdf

Decreto-legge 07 ottobre 2020, n. 125. G.U. Serie Generale, n. 248 del 07 ottobre 2020. Retrieved from: https://www.trovanorme.salute.gov.it/norme/dettaglioAtto?id=76574

D'Elia, F. (2019). The training of physical education teacher in primary school. Journal of Human Sport and Exercise, 14, pp. S100-S104. https://doi.org/10.14198//hse.2019.14.Proc1.12 
D'Elia, F. (2020). Teachers' perspectives about contents and learning aim of physical education in Italian primary school, Journal of Human Sport and Exercise, 15 (Proc2), pp. S279-S288. https://doi.org/10.14198/ihse.2020.15.Proc2.19

DPCM 08/03/2020 - (G.U. Serie Generale, n. 59 del 08 marzo 2020) Retrieved from: https://www.trovanorme.salute.gov.it/norme/dettaglioAtto?id=73594

Fumagalli, G. F., Tortella, P., Coppola, R., \& Sgrò, F. (2020). Physical or emotional scaffolding in a difficult motor task: What is better with 5-year-old children? Journal of Human Sport and Exercise, 15(4proc),S1436-S1445. https://doi.org/10.14198/hhse.2020.15.Proc4.40

Giallonardo, V., Sampogna, G., Del Vecchio, V., Luciano, M., Albert, U., Carmassi, C., et al. (2020). The impact of quarantine and physical distancing following COVID-19 on mental health: study protocol of a multicentric Italian population trial. Front. Psychiatr. 11:533. https://doi.org/10.3389/fpsyt.2020.00533

Guidelines on physical activity, sedentary behaviour and sleep for children under 5 years of age. Geneva: World Health Organization; 2019.

Haga, M., Tortella, P., Asonitou, K., Charitou, S., Koutsouki, D., Fumagalli, G., \& Sigmundsson, H. (2018). Cross-cultural aspects: Exploring motor competence among 7-to 8-year-old children from Greece, Italy, and Norway. Sage open, 8(2), 2158244018768381. https://doi.org/10.1177/2158244018768381

Janssen, I., LeBlanc, A.G., (2010). Systematic review of the health benefits of physical activity and fitness in school-aged children and youth. Int. J. Behav. Nutr. Phys. Act., 7, 40. https://doi.org/10.1186/1479$\underline{5868-7-40}$

King, AJ., Burke, LM., Halson, SL., \& Hawley, JA., (2020). The Challenge of Maintaining Metabolic Health During a Global Pandemic. Sport Medicine, 50, 1233-1241. https://doi.org/10.1007/s40279-020$\underline{01295-8}$

Notarnicola, A., Vicenti, G., Fischeti, F., Laricchia, L., Guastamacchia, R., Tafuri, S., Moreti, B. (2012). Improved mental representation of space in beginner orienteers. Perceptual and Motor Skills, 114 (1), pp. 250-260. https://doi.org/10.2466/03.04.11.PMS.114.1.250-260

Park, S., Kim, B., \& Lee, J., (2020). Social Distancing and Outdoor Physical Activity During the COVID19 Outbreak in South Korea: Implications for Physical Distancing Strategies. Asia Pacific Journal of Public Health, 32 (6-7), 360-362. https://doi.org/10.1177/1010539520940929

Roman-Viñas, B., Chaput, JP., Katzmarzyk, PT., Fogelholm, M., Lambert, E.V., Maher, C., Maia, J., Olds, T., Onywera, V., Sarmiento, O.L., et al., (2016). Proportion of children meeting recommendations for 24-h movement guidelines and associations with adiposity in a 12-country study. Int. J. Behav. Nutr. Phys. Act.13, 123. https://doi.org/10.1186/s12966-016-0449-8

Sgrò, F., Coppola, R., Tortella, P., \& Lipoma, M. (2020). Tactical Games Model as curriculum approach at elementary school: Effects on in-game volleyball technical improvements. Journal of Human Sport and Exercise, 15(4proc), S1178-S1186. https://doi.org/10.14198//hse.2020.15.Proc4.19

Sgrò, F., Mango, P., Pignato, S., Schembri, R., Licari, D., \& Lipoma, M. (2017). Assessing standing long jump developmental levels using an inertial measurement unit. Perceptual and motor skills, 124(1), 21-38. https://doi.org/10.1177/0031512516682649

Tortella, P., \& Fumagalli, G. (2017). The effect of teaching methodologies in promoting physical and cognitive development in children. Physical Activity and Educational Achievement: Insights from Exercise Neuroscience, 297. https://doi.org/10.4324/9781315305790-17

Tortella, P., Haga, M., Ingebrigtsen, J. E., Sigmundsson, H., \& Fumagalli, G. F. (2019). Comparing free play and partly structured play in 4-5-years-old children in an outdoor playground. Frontiers in public health, 7, 197. https://doi.org/10.3389/fpubh.2019.00197 
Tortella, P., Haga, M., Loras, H., Sigmundsson, H., \& Fumagalli, G. (2016). Motor skill development in Italian pre-school children induced by structured activities in a specific playground. PLoS One, 11(7), e0160244. https://doi.org/10.1371/journal.pone.0160244

Tremblay, M.S.; Carson, V.; Chaput, J.-P.; Connor Gorber, S.; Dinh, T.; Duggan, M.; Faulkner, G.; Gray, C.E.; Gruber, R.; Janson, K.; et al. Canadian 24-Hour Movement Guidelines for Children and Youth: An Integration of Physical Activity, Sedentary Behaviour, and Sleep. Appl. Physiol. Nutr. Metab. 2016, 41, S311-S327. https://doi.org/10.1139/apnm-2016-0151

W.H.O., (2008). Global recommendations on physical activity for health.

Zenic, N., Taiar, R., Gilic, B., Blazevic, M., Maric, D., Pojskic, H., Sekulic, \& D. (2020). Levels and changes of physical activity in adolescents during the COVID-19 Pandemic: Contextualizing urban vs. Rural living environment. Appl. Sci., 10, 3997. https://doi.org/10.3390/app10113997.

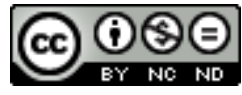

This work is licensed under a Attribution-NonCommercial-NoDerivatives 4.0 International (CC BY-NC-ND 4.0). 